This page intentionally left blank 
Günter Figal

\title{
Das Untier und die Liebe
}

\author{
Sieben \\ platonische Essays
}
J. B. Metzlersche Verlagsbuchhandlung Stuttgart




\title{
Bibliothek Metzler
}

Band 2

\section{CIP-Titelaufnahme der Deutschen Bibliothek}

\section{Figal, Günter:}

Das Untier und die Liebe : sieben platonische Essays / Günter Figal. Stuttgart : Metzler, I99I

(Bibliothek Metzler ; Bd. 2)

NE: GT

\author{
ISBN 978-3-476-00731-5 \\ ISBN 978-3-476-03337-6 (eBook) \\ DOI 10.1007/978-3-476-03337-6
}

Dieses Werk einschließlich aller seiner Teile ist urheberrechtlich geschützt. Jede Verwertung außerhalb der engen Grenzen des Urheberrechtsgesetzes ist ohne Zustimmung des Verlages unzulässig und strafbar. Das gilt insbesondere für Vervielfältigungen, Übersetzungen,

Mikroverfilmungen und die Einspeicherung und Verarbeitung in elektronischen Systemen.

(C) 1991 Springer-Verlag GmbH Deutschland Ursprünglich erschienen bei J. B. Metzlersche Verlagsbuchhandlung und Carl Ernst Poeschel Verlag GmbH in Stuttgart 1991 


\section{Vorwort}

Seite 9

I.

Das Untier und die Liebe

Die Frage nach sich selbst im Hinblick auf das Symposion

Seite II

II.

Das gute Leben als Leben im Möglichen

Zum Sinn von "gut « im Anschluß an den Philebos

Seite 3I

III.

Macht und Streit - Natur und Freundschaft

Rhetorik und Dialektik im Gorgias

Seite 49

IV.

Die bewiesene Unsterblichkeit

Über Ewigkeit und Endlichkeit im Anschluß an den Phaidon

Seite 7I

$\mathrm{V}$.

Warum soll man über die Welt eine Geschichte erzählen?

Der Timaios als Traktat vom Abbild

Seite 86 
VI.

Eine Frage der Zeit

Zwei »Gleichnisse " der Politeia

Seite rro

VII.

Im Spielraum des Schönen

Geliehene Rede nach Phaidros

Seite 128

Nachweise

Seite I44 


\section{Für Barbara}


Die durchsichtige Bildung ist die, an der unserem Blick Tiefe und Oberfläche zugleich einleuchten.

Ernst Jünger, Das abenteuerliche Herz

Zweite Fassung. 
Die in diesem Band versammelten Texte wollen in der Orientierung an den Dialogen Platons philosophische Perspektiven so entwikkeln, daß sich nicht nur Fachphilosophen und insbesondere Platonforscher angesprochen fühlen können. Sie nehmen sich darum das Recht, Platonische Gedanken in neue Kontexte zu stellen und verzichten auf die Darstellungsmittel einer wissenschaftlichen Abhandlung. Alle Texte sind für einen bestimmten Anlaß konzipiert oder doch so geschrieben, als ob sie für diesen Anlaß bestimmt wären: die Mehrzahl von ihnen wurde in der Evangelischen Akademie Hofgeismar im Rahmen von Tagungen vorgetragen, die dem Dia$\log$ im Anschluß an Platonische Dialoge gewidmet waren. Sie verdanken ihre Entstehung damit dem Initiator dieser Tagungen, meinem Freund Klaus Röhring, der als Direktor der Hofgeismarer Akademie den Spielraum eines lebendigen Gesprächs eröffnet hat; dafür sei ihm herzlich gedankt. Die als Vorträge gehaltenen Texte wurden für die Veröffentlichung in diesem Band überarbeitet und zum Teil neu geschrieben. Für die in jeder Hinsicht erfreuliche $\mathrm{Zu}$ sammenarbeit mit dem Verlag danke ich Bernd Lutz. Die Widmung dieses Buches sagt einen Dank, der keiner weiteren Erläuterung bedarf.

Günter Figal 